\title{
LETRAMENTOS DIGITAIS EM PLANOS DE AULAS DO PORTAL NOVA ESCOLA
}

\author{
DIGITAL LETTERING IN LESSON PLANS \\ FROM THE NEW SCHOOL PORTAL
}

\author{
Isabel Cristina da Silva Carneiro* \\ Williany Miranda da Silva**
}

\begin{abstract}
RESUMO: A cultura digital tem sido solicitada em várias instâncias da instituição escolar através do uso de materiais didáticos, aplicativos e plataformas educativas, dentre outras. Nesse sentido, este trabalho investiga as práticas letradas digitais de dois docentes, uma pedagoga e um professor de matemática, na regência de aulas com base nesse saber exigido. Para tanto, foi realizada uma pesquisa qualitativa, a partir da análise de entrevista semiestruturada e observação in loco de suas práticas, tomando por base a aplicação de planos de aula do portal Nova Escola. Os dados revelaram que os participantes da pesquisam fazem uso de aparatos tecnológicos (notebook, datashow e caixa de som) para ministração de aulas, mas que que tal uso ainda não representa práticas de letramentos digitais, revelando-se, então, a necessidade de reflexão sobre a mediação tecnológica necessária para o exercício da docência, com uso significativo do letramento digital, para além de uma ferramenta.
\end{abstract}

Palavras-chave: Letramentos digitais. Planos de aula. Portal Nova Escola.

ABSTRACT: The digital culture has been requested in several instances of the school institution through the use of teaching materials, applications and educational platforms, among others. In this sense, this work investigates the digital literacy practices of two teachers, a pedagogue and a mathematics teacher, in conducting classes based on this required knowledge. To this end, a qualitative research was carried out, based on the analysis of semi-structured interviews and on-site observation of their practices, based on the application of lesson plans from the Nova Escola portal. The data revealed that the research participants make use of technological devices (notebook, datashow and speaker) for teaching classes, but that such use does not yet represent digital literacy practices, thus revealing the need for reflection. on the technological mediation necessary for the exercise of teaching, with significant use of digital literacy, in addition to a tool.

Keywords: Digital literacies. Lesson plans. New School portal.

\section{Introdução}

A tecnologia está inserida na vida da maioria da população brasileira em todos os âmbitos. No contexto escolar não é diferente, tendo em vista que quase todos os alunos possuem celular/smartphone e o levam para a escola. No entanto, o foco dessa pesquisa recai nas práticas de letramentos digitais dos docentes. De acordo com Dudeney, Hockly e Pegrum (2016:62) "Se o primeiro passo para os professores é reconhecer os novos letramentos, o segundo é integrá-los a seu ensino cotidiano".

De acordo com dados do site Exame ${ }^{1}$, o Brasil é o quarto país do mundo em número de usuários de internet, possuindo cerca de 120 milhões de pessoas conectadas, resultando em uma frequência de acesso à rede em mais da metade de sua população. Partindo dessas informações, procuramos estudar a adesão dos professores às

\footnotetext{
* Mestranda em Linguagem e Ensino pela Universidade Federal de Campina Grande.

E-mail: isa_bel.ic@hotmail.com

${ }^{* *}$ Doutora em Letras pela Universidade Federal de Pernambuco (UFPE). E-mail:

williany.miranda@gmail.com

${ }^{1}$ Disponível em: https://exame.abril.com.br/tecnologia/brasil-e-o-4o-pais-em-numero-de-usuarios-deinternet/.
} 
facilidades tecnológicas em suas aulas, mais especificamente no que tange ao uso de planos de aula oriundos da web.

Planejar aulas é uma atividade que faz parte das atribuições do trabalho docente, refere-se à antecipação detalhada do que será feito, visando alcançar um determinado objetivo pautado sempre em melhorar o processo de ensino-aprendizagem. Libâneo (2013:86-87) afirma que "O professor planeja, dirige e controla o processo de ensino, tendo em vista estimular e suscitar a atividade própria dos alunos para a aprendizagem." Tendo em vista tal importância, nosso olhar direcionou-se para o contexto do plano de aula disponibilizado por uma plataforma digital, o portal Nova Escola, aos anos finais do ensino fundamental I e II ( $4^{\circ}$ e $9^{\circ}$ anos, respectivamente).

A partir do exposto, este artigo pretende responder ao questionamento: Que práticas letradas digitais são reveladas pelos professores do ensino fundamental ao fazerem uso dos planos de aula do portal Nova Escola? Essa problemática surgiu da necessidade de entender a inserção da cultura digital no universo particular da regência de aulas de dois professores: uma pedagoga e um professor de matemática. Este selecionou um plano de aula para a turma de $9^{\circ}$ ano, e aquela, um de linguagem, tendo em vista ser professora polivalente em uma turma de $4^{\circ}$ ano. Esse estudo justifica-se por preencher uma lacuna no que se refere às práticas letradas digitais de professores em contextos escolares, sinalizadas como estritamente fundamentais ao ensino, conforme sinaliza a Base Nacional Comum Curricular (BNCC, 2017)2.

Além da presente introdução, o artigo contém uma seção que discute os fundamentos teóricos sobre letramentos digitais (BUZATO, 2006;2007; DUDENEY, HOCKLY E PEGRUN, 2016) e plano de aulas (VASCONCELLOS, 2002; GASPARIN, 2007; TORMENTA E FIGUEIREDO, 2010; LIBÂNEO, 2013), bem como outras duas seções que dão conta da metodologia e análise dos dados, respectivamente. Para concluir, duas outras seções, a de considerações finais e as referências utilizadas.

\section{Fundamentos teóricos sobre letramentos digitais e plano de aulas}

Para a presente seção, nosso intuito é discutir a respeito de conceitos fundamentais para nossa categoria de análise que são, respectivamente, o de letramentos digitais e o de plano de aulas. Assim, dividimos a seção em duas: "Letramentos digitais e a atuação docente" e "Plano de aulas na esfera da virtualidade"

\subsection{Letramentos digitais e a atuação docente}

Já não é mais novidade que as tecnologias adentraram com muita intensidade na escola e os professores podem fazer uso delas com o intuito de melhorarem suas aulas, principalmente tendo em vista a gama de informações contidas na rede e que podem subsidiar o seu trabalho, a exemplo dos planos de aula prontos, pelo fato de serem facilmente baixados, adaptados e levados para a aula, ou deles podem ser retirados textos, imagens, ideias ou conceitos. No entanto, de acordo com Rezende (2016:10) "a inserção desses recursos nas escolas não vem acompanhada de mudanças nas perspectivas de ensino".

O problema é que, muitas vezes, há uma certa resistência por parte de alguns professores ou da própria instituição escolar em vislumbrar o uso de aparatos

${ }^{2}$ Data oficial da BNCC que corresponde ao ensino fundamental. 
tecnológicos enquanto auxiliadores do trabalho docente. Fazer uso do datashow acaba sendo uma das únicas ferramentas tecnológicas levada para as aulas, havendo uma exposição de conteúdos em slides, semelhante à exposição que o livro didático apresenta, no caso, apenas o meio foi alterado sem existir, de fato, um comportamento diferenciado ao usar a tecnologia, pois como elucida Rojo (2009:08) "se os textos da contemporaneidade mudaram, as competências /capacidades de leitura e produção de textos exigidas para participar de práticas de letramento atuais não podem ser as mesmas".

A postura do professor perante as inovações tecnológicas varia segundo suas práticas letradas digitais. Para entender melhor essa nomenclatura torna-se fundamental expor um pouco a respeito dos Novos Estudos do Letramento(s) para adentrarmos nos conceitos de Letramentos Digitais que subsidiam este estudo.

Os Novos Estudos do Letramento(s) tiveram início com os importantes estudos de Street. Ele frisava que ser alfabetizado não coincidia, necessariamente, com ser letrado, termos vistos, durante muito tempo, como sinônimos. $\mathrm{O}$ autor ainda tratou que o letramento deve desenvolver as habilidades de leitura e escrita nos mais diversos contextos sociais e não de maneira isolada e descontextualizada, como costumeiramente ocorre na escola.

Partindo desses estudos pioneiros, começaremos a tratar de alguns conceitos de Letramentos Digitais que nortearam a presente pesquisa. Iniciamos apresentando o de Dudeney, Hockly e Pegrum (2016:17), para eles, letramentos digitais são "habilidades individuais e sociais necessárias para interpretar, administrar, compartilhar e criar sentido eficazmente no âmbito crescente dos canais de comunicação social". Essa definição deixa transparecer o viés social presente nas práticas letradas digitais, pois envolve "ter acesso a vaga de emprego nas economias pós-industriais de conhecimento e assumir papéis como cidadãos globais confortáveis em lidar com diferenças interculturais (...)", ou seja, vai além do manuseio por si só das ferramentas digitais, por exemplo, refere-se à função social que as tecnologias assumem nas mais diversas situações intra e extraescolar.

Um livro que foi digitalizado, por exemplo, não é considerado um material digital tendo em vista que não houve mudança em relação às práticas de leitura mas em seu suporte. Dessa maneira, o usuário que lê textos em $p d f$ não pode ser considerado, impreterivelmente, letrado digital, pois é imprescindível a capacidade "de avaliar e usar a informação de forma crítica se quiserem transformá-la em conhecimento" (BUCKINGHAM, 2010:49).

O conceito de Buzato (2006:09), anos antes do de Dudeney, Hockly e Pegrum (2016), já enfoca as práticas sociais associadas ao conceito de Letramentos Digitais. Segundo ele,

Letramentos digitais (LDs) são conjuntos de letramentos (práticas sociais) que se apóiam, entrelaçam, e apropriam mútua e continuamente por meio de dispositivos digitais para finalidades específicas, tanto em contextos socioculturais geograficamente e temporariamente limitados, quanto naqueles construídos pela interação mediada eletronicamente.

Assim, não se está desconsiderando os outros tipos de letramentos, principalmente tendo em vista que o impresso tem sido muito usado e dado bons resultados em várias circunstâncias, entretanto, enfocamos que o letramento digital é quase uma necessidade na sociedade atual. Então, surge uma outra questão: a escola, 
por vezes, não oferece suporte ao docente, como recursos tecnológicos e formação continuada na área.

Ser letrado digital corresponde a "praticar as tecnologias digitais, respondendo ativamente seus diferentes propósitos, em diferentes contextos" (RIBEIRO; FREITAS, 2011:67), ou seja, “(...) é muito mais do que saber usar o computador, usar o teclado, é saber localizar, selecionar, filtrar e avaliar informações disponibilizadas digitalmente" (SCHONS; VALENTINI, 2012:07). O que está posto em questão é que, devido às mudanças ocorridas na sociedade com relação às tecnologias e que acarretaram inclusive mudanças no alunado, "Ensinar língua exclusivamente através do letramento impresso é, nos dias atuais, fraudar nossos estudantes no seu presente e em suas necessidades futuras" (DUDENEY; HOCKLY; PEGRUM, 2016:19).

Em parte, a dificuldade dos professores no tocante às tecnologias pode estar relacionada ao fato de alguns serem imigrantes digitais (PRENSKY, 2001), ou seja, por estarem migrando das tecnologias impressas para as chamadas novas tecnologias. Segundo Souza (2013), algumas características são: arquivar ou imprimir e-mails, a internet ser a segunda fonte de pesquisa, imprimir documentos para realizar modificações e depois digitá-las no computador, enviar e-mails e depois ligar ou enviar mensagem confirmando o recebimento.

Outros docentes são nativos digitais, termo usado para referir-se aos usuários mais hábeis da tecnologia (PRENSKY, 2001). Estes, possivelmente, têm uma desenvoltura melhor em inserir os aparatos tecnológicos de maneira mais eficiente em suas aulas tendo em vista que buscam informações em jornais online em vez dos impressos, assistem vídeos, realizam leituras em sites ou blogs, possuem bibliotecas digitais, fazem uso de aplicativos para conversar como o WhatsApp, por exemplo, ouvem músicas online e até conhecem pessoas por intermédio da rede (SOUZA, 2013).

$\mathrm{Na}$ seção seguinte, tratamos a respeito do conceito de plano de aulas e sua relação com o ambiente digital.

\subsection{Planos de aula na esfera da virtualidade}

Planejar faz parte da maioria da vida dos seres humanos: planeja-se uma viagem, um casamento, o melhor momento para se ter um filho, comprar um carro, um imóvel, enfim, tudo precisa ser planejado para poder dar certo de maneira mais organizada. Com relação ao ambiente escolar, a ideia de planejamento envolve processos e objetos não espontaneístas, que se referem à profissionalização do professor, que planeja de maneira escrita, mental ou oral, através de planos de aula, o que irá fazer perante a realidade de sua turma (VASCONCELLOS, 2002).

As pesquisas sobre planos de aula são mais recorrentes na didática, por esse motivo faremos uso de alguns autores dessa área. Inicialmente, traremos conceitos sobre o tema. Tormenta e Figueiredo (2010:02) nomeiam o plano de aula como Plano de Trabalho Docente e afirmam ser "o espaço onde o professor define as ações, os meios para realizá-las bem como as formas de avaliar se os resultados esperados foram atingidos em cada turma", dessa forma, percebemos que, para os autores, o material didático em questão é mais que um documento burocrático, trata-se da profissionalização docente, sendo, então, uma das atribuições do trabalho desse profissional. Acerca da importância do Plano de Trabalho Docente, Tormenta e Figueiredo (2010: 02-03) relatam que muitos professores não o veem enquanto 
A parte mais importante do processo pedagógico, é ali que o docente irá realizar todo o processo de ensino, é nesse momento que ele identifica todas as dificuldades e a realidade de seus discentes. $\mathrm{O}$ Plano de Trabalho Docente é ferramenta que ampara e determina o modo de ação do docente, sem essa ferramenta corre o risco de não desenvolver seu trabalho de ensinar e transformar os discentes. Sem o planejamento não se tem uma visão geral do todo e isso muitas vezes se revela e reflete contra o próprio docente.

O trecho revela o quanto o planejamento deve ser um momento de reflexão da prática do professor além de ser um auxiliador para que se conheça e procure sanar as dificuldades dos discentes. Também nos remete a um processo, algo construído e não um produto, visão também compartilhada por Vasconcellos (2002), que coloca o plano de aula, assim como o plano de curso, no que ele denomina de Projeto de EnsinoAprendizagem e afirma ser esse o mais próximo da prática docente.

Para Vasconcellos (2002:148), o planejamento está no campo da reflexão e revela as teorias subjacentes às práticas dos professores, não sendo neutro. $\mathrm{O}$ documento que materializa o planejamento é o plano de aula, que é "a proposta de trabalho do professor para uma determinada aula ou conjunto de aulas (...). É a orientação para o que fazer cotidiano". Esse é um conceito mais geral trazido pelo autor para o material em questão, ou seja, um trabalho que antecede a prática, é o momento em que o professor reflete e programa o que pretende fazer em uma aula ou em um conjunto delas. Para tanto, é necessário que o docente conheça a realidade de seus alunos para poder atuar de maneira ainda mais ativa no processo de ensino-aprendizagem, tendo em vista que o material didático aqui tratado atua "como ferramenta essencial e necessária na prática pedagógica direcionada a uma ação consciente e transformadora" (TORMENTA; FIGUEIREDO, 2010:04).

De acordo com Libâneo (2013:92), o planejamento do professor culmina na aprendizagem, pois "A aprendizagem escolar é uma atividade planejada, intencional e dirigida, e não casual e espontânea", entretanto, levando em consideração a atual conjuntura social, em que as tecnologias digitais fazem-se presentes no cotidiano das pessoas, há facilidade em encontrar planos de aulas prontos e gratuitos na web, pois muitos sites já os disponibilizam. Cabe ressaltar que, mesmo havendo tal facilidade, nada substitui o planejamento do professor. Vasconcellos (2002:148) afirma que "Não planejar pode implicar perder possibilidades de melhores caminhos, perder pontos de entrada significativos". Entretanto, os professores observados em nosso estudo não realizaram adaptações nos planos escolhidos.

Gasparin (2007:111-112) destaca algumas atitudes que o professor precisa antes de preparar sua aula: "Predisposição mental sobre o que vai executar com seus alunos em relação aos conteúdos, os processos pedagógicos que pretende utilizar, os recursos necessários e as formas de avaliação". A partir disso, percebe-se que o plano de aula é prototípico, até porque pertence a um gênero textual e por isso necessita de uma estrutura fixa: tema; conteúdo, objetivos, metodologia, duração, recursos, avaliação e tarefa.

Os planos de aula do portal Nova Escola são considerados materiais didáticos digitais pois estão presentes na rede, apresentando, por isso, características peculiares ao suporte em questão, e podem representar um complemento para a atuação do professor (ROJO, 2013).

No tópico seguinte, apresentamos o percurso metodológico seguido e caracterizamos, de maneira sucinta, como os planos de aula do portal Nova Escola são constituídos. 


\section{Aspectos metodológicos}

Com o objetivo de identificarmos práticas letradas digitais de professores ao fazerem uso dos planos de aula do site Nova Escola, fizemos um estudo de casos múltiplos $^{3}$ (YIN, 2001), tendo em vista termos duas unidades de análise. Como técnicas/instrumentos de geração de dados usamos a observação in loco e a entrevista semiestruturada. Observamos duas aulas de professores distintos em diferentes datas para tentar conhecer melhor como se dão suas práticas letradas digitais. Sendo assim, nossa pesquisa é de natureza descritiva e de base qualitativa.

O portal Nova Escola é um ambiente gratuito e destinado para os profissionais que trabalham na educação, disponibiliza cursos, notícias, atividades, jogos e planos de aula para subsidiar o trabalho docente. Com relação aos planos de aula, o ambiente contém materiais destinados a todas as disciplinas, da educação infantil até os anos finais do fundamental II. Para acessar o portal, o cadastro é opcional.

Os planos de aulas do ambiente em questão estruturam-se de maneira diferenciada do que propõe a teoria, continuam apresentando os mesmos elementos (conteúdo, objetivos, tarefa, duração etc), no entanto, constituem-se por slides e orientações, como será possível perceber através da figura 01, "Caracterização dos planos de aula":

Figura 01: Caracterização dos planos de aula

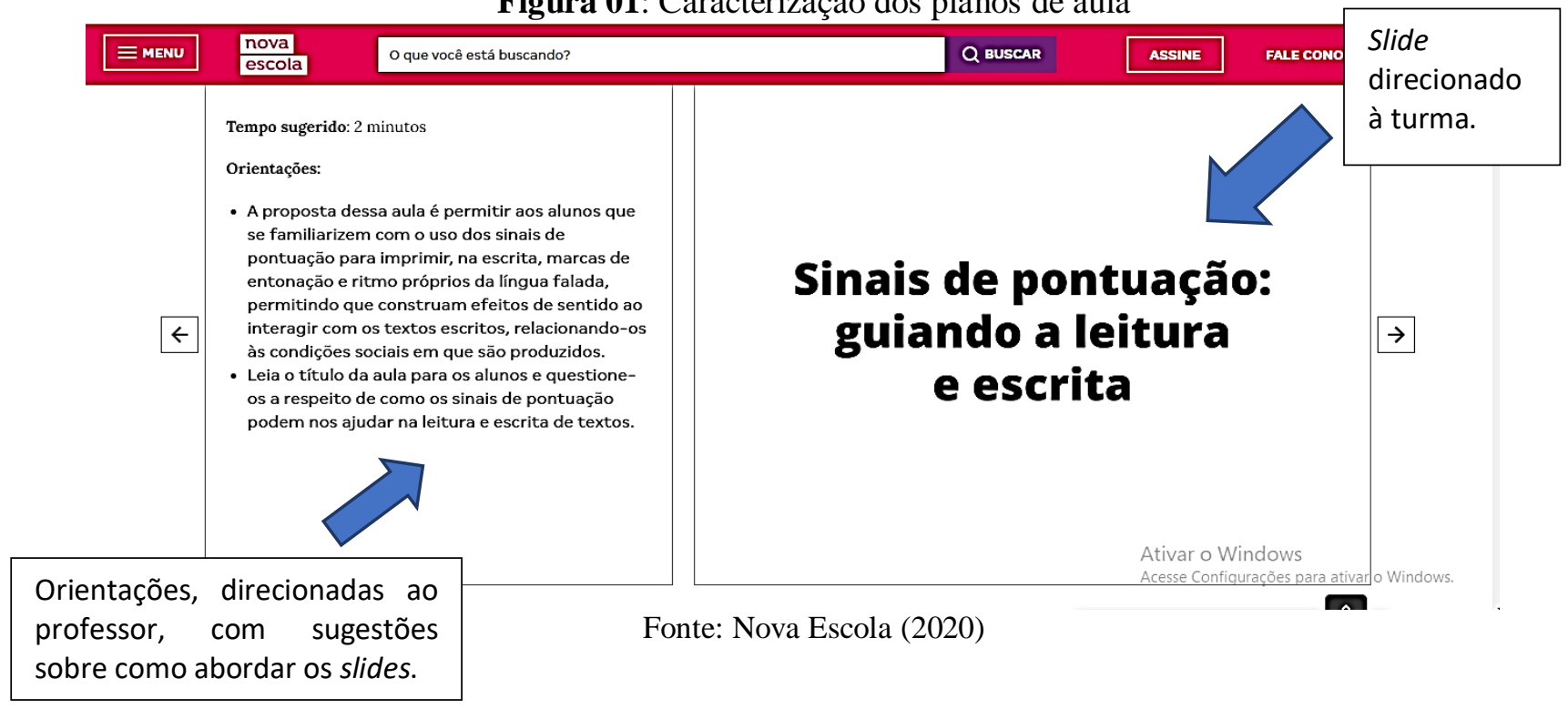

Então, como é possível visualizar por meio da figura 01, os slides referem-se à aplicabilidade do material, destinam-se ao alunado e contém atividades, desafios e teorias. As orientações possuem teor procedimental e são restritas ao docente. Elas contêm referências para aprimoramento, indagações que podem ser feitas aos discentes, materiais complementares e links para acessar vídeos ou textos que possam enriquecer a aula. Assim, o que o portal denomina como plano de aula é a junção dos slides e das orientações. Ao usuário é permitido acessar os planos de maneira online no site e

\footnotetext{
3 Artigo vinculado ao projeto de pesquisa Configurações de Ensino em Práticas Multidisciplinares de Linguagem (ns) (2018-2022) - Plataforma Brasil CAAE nº 94344318.6.0000.5182.
} 
realizar o download em power point para adaptar, caso necessário, e em $p d f$, se o interesse for realizar consultas no material sem o intuito de modificá-lo.

Voltando à coleta dos dados, a entrevista foi composta por perguntas relacionadas à aplicação do plano de aula escolhido, envolvendo dificuldades encontradas, sugestões e também questionamentos que envolvessem a inserção da tecnologia enquanto ferramenta auxiliadora do trabalho docente. A entrevista com o professor de matemática ocorreu no dia 10 de julho, após o final da aula observada, em uma das salas vazias da própria escola. A entrevista da pedagoga ocorreu três dias depois da observação, no dia 14 de julho, na residência da docente. Por motivos pessoais, ela não pode ficar após a aula no dia em que a observação ocorreu para responder às perguntas.

Os participantes trabalham em escolas públicas, uma é municipal e outra estadual, ambas localizadas na cidade de Queimadas-PB. A professora da escola municipal, a quem chamaremos de $\mathrm{A}$, é estudante do quinto período do curso de pedagogia e ministra aulas em uma turma de $4^{\circ}$ ano. O plano de aula escolhido por ela foi de língua portuguesa sobre sinais de pontuação ${ }^{4}$ e a aula foi ministrada no dia 11 de julho de 2019.

O professor da escola estadual, a quem chamaremos de B, é formado em matemática e ministra aulas em turmas do ensino fundamental e médio. A turma escolhida para aplicar o plano de aula foi do $9^{\circ}$ ano, pois é a única do ensino fundamental em que esse professor leciona e o portal Nova Escola não disponibiliza, até o momento, planos para o ensino médio. $\mathrm{O}$ material selecionado pelo docente referiu-se à proporcionalidade ${ }^{5}$. A aula foi ministrada no dia 10 de julho de 2019.

O critério para a escolha desses profissionais para observação das aulas foi a disponibilidade em participar da pesquisa assim como a curiosidade em investigar as práticas de professores de níveis e áreas de ensino distintos: pedagoga e professor de fundamental II.

Foram realizadas entrevistas semiestruturadas com o intuito de saber o ponto de vista dos professores ao fazerem uso dos planos de aula do site e, assim, complementar as informações obtidas durante as observações. Segundo Klein e Damico (2014:78) "As entrevistas passaram a se constituir em um importante instrumento de investigação, utilizadas na busca por informações ou sujeitos/informantes específicos".

No exame dos dados, utilizamos a Análise do Conteúdo (BARDIN, 1977) para interpretar o que ficou subtendido nas respostas dadas nas entrevistas em consonância com a prática de sala de aula observada.

Dessa maneira, possuímos dois conjuntos de dados: as anotações referentes às observações da aplicação dos planos e a entrevista realizada após tal aplicação.

\section{Análise dos dados}

Esta seção reserva-se à análise da observação das aulas em articulação com dados coletados durante a entrevista. Temos duas subseções, na primeira delas, intitulada "Aplicação dos planos de aulas: explanação dos slides", abordamos a aplicação dos planos e a associamos a algumas respostas dadas na entrevista. $\mathrm{Na}$ segunda, "Práticas letradas digitais dos docentes", nosso foco residiu na análise das

\footnotetext{
${ }^{4}$ Disponível em: https://novaescola.org.br/plano-de-aula/3514/identificando-sinais-de-pontuacao. ${ }^{5}$ Disponível em: https://novaescola.org.br/plano-de-aula/1727/grandezas-diretamente-proporcionais.
} 
práticas letradas digitais dos dois professores durante a aplicação do plano de aula que cada um escolheu.

\subsection{Aplicação dos planos de aula: explanação dos slides}

A análise se inicia a partir do que foi observado nas aulas. Os dados revelaram que ambos os professores sabem manusear com maestria os aparatos tecnológicos, a exemplo do datashow, computador e caixa de som, isso se explica pelo fato de, como foi respondido na entrevista, já fazerem uso de tais instrumentos em suas aulas. Entretanto, de acordo com Rezende (2015), nem sempre a inserção dos aparatos tecnológicos corresponde a uma mudança, de fato, do ensino.

Partindo da premissa de que o conceito de letramentos digitais implica práticas sociais(BUZATO, 2006; DUDENEY; HOCKLY; PEGRUM, 2016), notamos algumas questões relativas à aplicação dos planos de aula do portal Nova Escola.

A primeira observação foi da aula de matemática do professor B e, no dia seguinte, da professora A. O primeiro fez uso do slide articulando as teorias tratadas no tocante à proporcionalidade atreladas à realidade dos alunos, partindo de questionamentos contidos no próprio material didático em questão, assim como a professora A, cujo tema tratado envolvia pontuação, também relacionado ao dia a dia dos discentes.

A explanação dos assuntos foi muito didática, pois ambos partiam das inquietações da turma e as associavam ao conteúdo dos slides, criando pontes entre o que estava posto e a vida deles, segundo Libâneo (2013), partir do conhecimento prévio dos discentes facilita a compreensão do novo assunto, sendo favorável no processo de ensino-aprendizagem. $\mathrm{O}$ professor $\mathrm{B}$, ao fazer uso dos exemplos trazidos no material, também mudava dados para que os alunos assimilassem melhor o conteúdo. A figura 02, "Proporcionalidade envolvendo uma receita de bolo", exemplifica o que expomos:

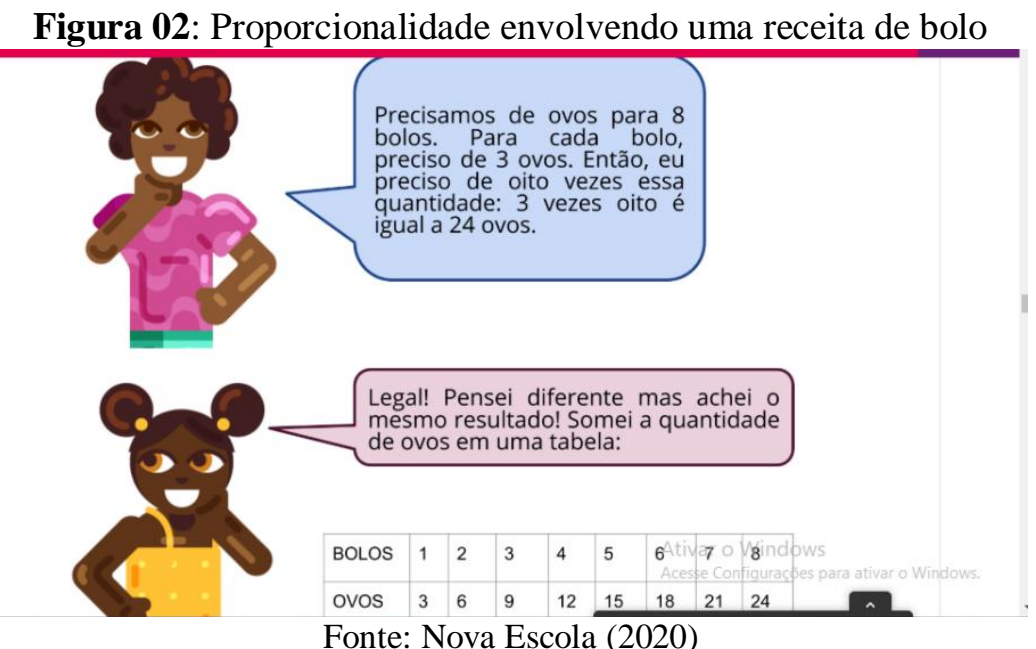

Como é possível observar na figura 02 , o slide traz alguns dados: alguém iria fazer 8 bolos e para cada bolo seriam usados 3 ovos. Para sintetizar melhor, o professor B modificava a quantidade de bolos e também de ovos, por exemplo, em determinado momento da aula, ele pediu para que os alunos refletissem sobre quantos ovos seriam necessários para fazer 12 bolos, sendo que em cada um seriam usados 4 ovos.

Esse ponto foi interessante pois a aula inteira girou em torno de exemplos e atividades sobre um mesmo tema: quantidade de ingredientes para receitas de bolo, prática que, segundo o docente, em resposta a uma das perguntas da entrevista, 
informou não ser rotineira, pelo fato de não gostar de ficar "remoendo" assunto por muito tempo, como podemos perceber no trecho: "Eu acho que mudou um pouco a minha forma de ensinar porque aquilo que os meninos falaram, ele repete muito e eu não tenho essa tendência, entendeu?".

Em contrapartida, a professora A tendia a ficar mais tempo procurando pistas de que os alunos assimilaram bem o que foi apresentado antes da mudança de slides, ação que ela, em conversa informal, considera benéfica para a faixa etária com a qual atua. Assim como no plano de aula do $9^{\circ}$ ano, o do $4^{\circ}$ possuía muitas imagens que foram explanadas através da mediação docente e, diferentemente do plano de aula de matemática, possuía links para acesso a um vídeo e a textos complementares, como é típico de materiais didáticos digitais (ROJO, 2013). A apreciação dos detalhes presentes em cada um dos materiais (como cores, trechos de textos ou de problemas, etc.) constituiu-se como instrumento importante para suscitar debates e a assimilação do conteúdo fruir de maneira mais produtiva/reflexiva. Abaixo estão alguns exemplos das imagens presentes nos slides:

Figura 03: Sinais de trânsito

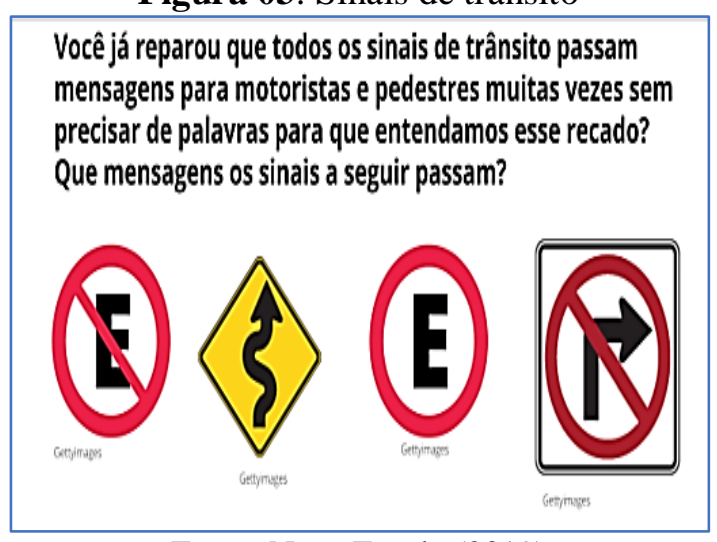

Fonte: Nova Escola (2019)

Figura 04: Bolo de aniversário

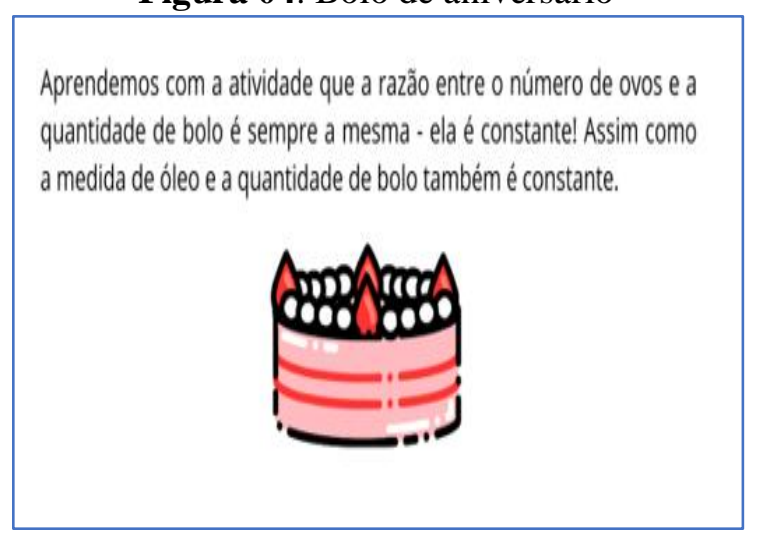

Fonte: Nova Escola (2019)

Na figura 03, "Sinais de trânsito", há indagações sobre pontuação e, para respondê-las, o aluno precisa ativar seus conhecimentos prévios com base nas placas de

\footnotetext{
${ }^{6}$ Termo usado pelo professor em conversa informal.
} 
trânsito. Na figura 04, "Bolo de aniversário", contemplamos uma síntese do conteúdo de matemática partindo de uma receita de bolo.

Durante a observação, foi possível perceber bastante empolgação dos alunos do $9^{\circ}$ ano com a aula, gostaram dos exemplos pois falavam de uma receita para bolo e eles começaram a pensar a respeito dos materiais usados para preparar um e sobre suas respectivas quantidades. A questão de haver imagens e um diálogo de personagens no slide, conforme exposto na figura 02, chamou muito a atenção deles, embora esse ponto não tenha sido focalizado pelo educador. O plano de aula escolhido pelo professor $\mathrm{B}$ apresentou muitos exemplos de fixação e a grande maioria dos alunos comentou haver entendido melhor o conteúdo, inclusive pediram para que o docente trouxesse mais aulas como aquela. Assim, o objetivo foi alcançado: a aprendizagem (LIBÂNEO, 2013).

Um último ponto muito importante também relatado na entrevista do professor B reside no fato de citar que o plano de aula do site Nova Escola o levou a refletir sobre sua prática, pois não era de seu costume detalhar tanto suas explicações, como é possível perceber no trecho "Então isso me faz também refletir sobre a minha prática, eu sou muito direto (risos) e talvez eles tenham sentido essa diferença da minha aula pra que eu dei hoje". Então, mesmo com um material pronto disponibilizado na internet, a reflexão pode ocorrer e contribuir para melhorias em aulas futuras, o que culmina no aprendizado do discente (TORMENTA; FIGUEIREDO, 2010).

\subsection{Práticas letradas digitais dos docentes}

Nesta seção, tratamos a respeito do que foi observado nas aulas e apreendido por meio da entrevista no tocante às práticas letradas digitais dos professores estudados.

Com relação à observância da pedagoga, foi perceptível que o datashow costuma ser usado com frequência na turma pois os alunos logo fizeram um círculo quando ela começou a montá-lo, como se tal prática já fizesse parte de uma rotina.

Antes de adentrar no conteúdo propriamente dito, a professora A apresentou o tema da aula através da escrita, no quadro, de uma determinada frase por duas vezes, em uma delas colocou a vírgula e na outra não. Em seguida, questionou-os a respeito do sentido que o sinal de pontuação causara no enunciado, as frases foram: "Respeite meus cabelos brancos" e "Respeite meus cabelos, brancos". Após a participação de grande maioria houve a abordagem dos slides constitutivos do plano de aula escolhido.

O segundo slide continha um vídeo sobre o trânsito em uma cidade populosa da Índia, local em que não havia semáforos e, por isso, causava desordem na passagem nos veículos e da própria população. O objetivo seria o de associar essa informação a um texto sem pontuação para que os discentes refletissem a respeito disso, criando intertextualidade. O problema é que, mesmo havendo sinal de Wi-fi na escola, o vídeo não abriu devido à internet estar com sinal ruim. A docente não havia feito download em casa. Tendo assim, o debate ocorreu a partir da observação da imagem de abertura do vídeo, que aparece na figura 05, "Trânsito na Índia": 

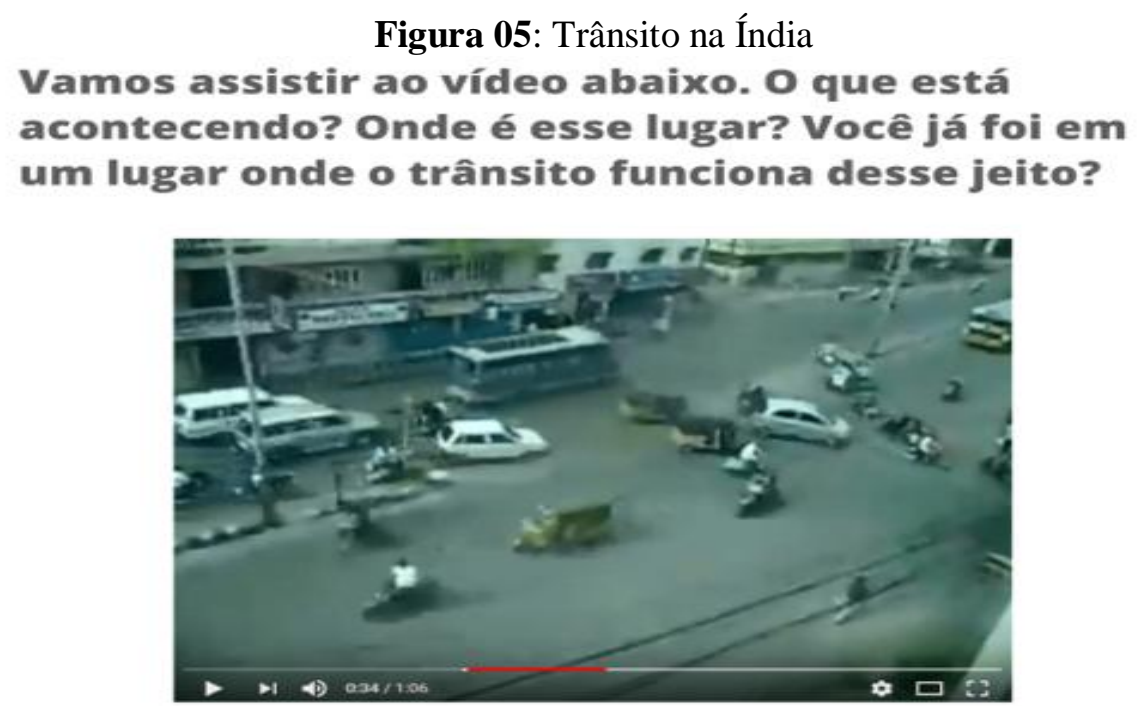

Fonte: Nova Escola (2019)

No entanto, foi notório que houve um certo prejuízo a ausência do vídeo na aplicação do plano de aula. A professora A afirmou, em uma das questões da entrevista sobre a frequência com que produzia planos de aula, que sempre costuma planejar, conforme o trecho "Sim, sempre faço planos de aula, semanalmente e por escrito. Eu tenho um caderno que é o que eu anoto lá meus planos de aula e toda semana eu faço e é anotado nele".

Entretanto, a ausência de um "plano B" para a visualização do vídeo pareceu não ser pensada anteriormente, pois cabe ao professor pensar nas ações a serem realizadas e o meio de torná-las possível (TORMENTA; FIGUEIREDO, 2010; LIBÂNEO, 2013).

A questão da falta de internet na escola não se limita apenas ao contexto da professora A, diversos outros docentes podem sentir-se prejudicados pois é uma realidade frequente em diversas escolas públicas do país. Então, é difícil haver práticas letradas digitais quando a própria escola não oferece os subsídios necessários para isso.

O plano escolhido pelo professor B não fazia uso de links ou vídeos, baseava-se em um diálogo pautado em uma situação cotidiana envolvendo proporcionalidade, havia imagens de personagens envolvidos na conversação. O professor enfocou o conteúdo, lia as falas dos balões (que traziam conceitos importantes para a disciplina, como se pode observar na figura 06) mas em nenhum momento fez referência aos personagens do diálogo enquanto complementadores da formação do sentido da aula. Foi bastante semelhante a leitura que se faz de um conteúdo no livro didático. A figura 06, "Diálogo", contempla o conceito de "grandezas", 
Figura 06: Diálogo

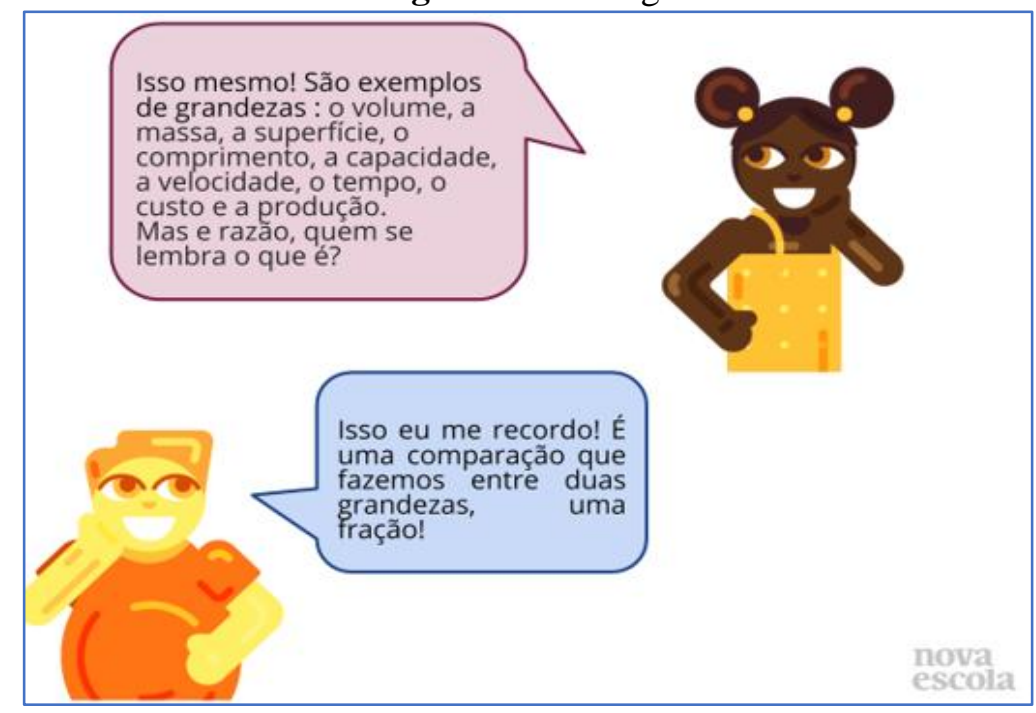

Fonte: Nova escola (2019)

A desenvoltura ao fazer uso de um material pronto, a princípio, não pareceu incomodar o profissional, no entanto, durante a entrevista ele relatou que o plano "ele repete muito e eu não tenho essa tendência", isso revela que, para alguns profissionais, fazer o próprio plano de aula, seja ele mental ou escrito (VASCONCELLOS, 2002), pode ser uma ação mais promissora, ou adaptar o material encontrado na web antes de levá-lo para a aula, principalmente tendo em vista a gama de materiais que podem ser encontrados nos mais diversos sites.

O professor em questão diz que materiais oriundos da internet podem auxiliar o trabalho docente, mas que é preciso filtrar o que, de fato, os alunos precisam, o trecho sinaliza o que expomos "a internet digamos que ela é... ela é um ambiente muito vasto de (...) conhecimento, né? (...) praticamente tudo tá lá e cabe ao professor é... filtrar, né?". Então, a seleção e adaptação de materiais faz parte da autonomia do usuário, (BARTON; LEE, 2015), no entanto, tal ação não foi feita por ele.

Ao ser perguntado sobre haver feito alguma alteração no plano de aula usado, ele disse não ter feito nenhuma por se encaixar nos propósitos da turma mas propôs algumas alterações para aulas futuras, caso fosse usá-lo novamente, como a inclusão de uma lista de exercícios no próprio slide e foi exatamente esse último apontamento do docente que nos levou a refletir um pouco mais.

Essa é uma ação que poderia ser feita em outro meio que não o slide, tendo em vista que seria uma atividade dirigida convencional, como as trazidas nos livros didáticos, partindo da premissa de que o professor não citou em nenhum momento se a lista proposta teria elementos multimídia ou se seriam as questões transcritas, pois caso sejam, haveria apenas uma mudança do meio: do livro para o slide, não caracterizando uma prática letrada digital (REZENDE, 2016).

Com relação à pedagoga, alguns dos slides do plano de aula escolhido traziam excertos de fábulas e um outro trouxe o link de um conto que deveria ser lido com a turma. A professora não havia impresso o texto, então o leu fazendo uso do smartphone, pois havia salvo no aparelho, característica comum dos nativos digitais que é a leitura em tela em substituição ao papel (Souza, 2013). Ela comentou, após o fim da entrevista, que sempre que há a necessidade permite que os alunos façam pesquisas no celular, seja de alguma palavra que não saibam o significado, de algum vídeo ou imagem que enriqueçam a aula. 
Como as crianças que ensina são carentes e, muitas vezes, não estão com internet, ela própria usa seu aparelho para realizar tal tarefa, o que está de acordo com o conceito de letramentos digitais segundo Dudeney, Hockly e Pegrum (2016), pelo fato de não se limitar a manusear aparelhos tecnológicos, mas a atribuir função a seu uso.

No fim dos slides da professora A, constava uma atividade para ser realizada em grupo, mas que não ocorreu devido à ausência do texto impresso (o mesmo que a professora esqueceu de imprimir), ela informou que seria feita na aula seguinte, que não foi observada. A necessidade de haver um texto impresso para a realização de uma atividade demonstra que, mesmo estando em um ambiente digital, o plano de aula apresenta o apego ao impresso em diversos momentos das orientações e, de maneira mais específica, no fechamento dessa aula.

\section{Considerações finais}

Neste estudo, procuramos responder ao seguinte questionamento: Que práticas letradas digitais são reveladas pelos professores do ensino fundamental ao fazerem uso dos planos de aula do portal Nova Escola? Os dados nos revelaram que os docentes procuram modificar sua prática e inserir aparatos tecnológicos em suas aulas, mas é imprescindível afirmar que o uso propriamente dito desses aparatos não necessariamente os enquadra enquanto letrados digitais, pois essas envolvem práticas sociais atreladas ao uso destes aparatos e não apenas seu manuseio.

Como objetivo geral nos propusemos a conhecer práticas letradas digitais de dois docentes, uma pedagoga e um professor de matemática, na regência de aulas pautadas na tecnologia, podemos dizer que ele foi alcançado tendo em vista que a observação das aulas ocorreu e foi possível perceber a postura do professor ao fazer uso de um material didático oriundo da web capaz de revelar suas práticas letradas digitais: atuaram como imigrantes digitais pelo fato de haver dificuldades em desvencilhar-se da tecnologia impressa para a digital (BARTON; LEE, 2015), tal constatação se fortalece tendo em vista que um deles, a professora A, imprimiu-o e levou para a aula, .

Nossos objetivos específicos eram identificar práticas letradas digitais dos professores ao fazerem uso de planos de aula do portal Nova Escola e verificar de que forma tais planos atuam como facilitadores da prática docente. Esses objetivos também foram alcançados pois a observação das aulas nos permitiu criar um perfil dos docentes quanto ao uso da tecnologia e, dessa forma, percebermos a funcionalidade dos planos de aula usados por ambos: facilitadores por não precisar o professor preparar o próprio material, mas isso não quer dizer que adaptações não precisassem ser feitas.

Os dados nos levaram a refletir acerca da importância de haver formação continuada para os docentes no que diz respeito à inserção da tecnologia no ambiente escolar, principalmente tendo em vista a implantação da BNCC, que passa a exigir do profissional o conhecimento do uso de aparatos tecnológicos não apenas voltado para seu manuseio mas para a criação do senso crítico nos alunos.

O que pudemos observar nas aulas em que participamos foi que a adesão ainda é tímida, o professor de matemática demonstrou um vasto conhecimento no que diz respeito a saber baixar materiais da web, visitar sites diversos, usar aparelhos eletrônicos (em conversa informal, comentou possuir um canal no youtube). A pedagoga mostrou conhecimentos semelhantes, mas diferenciando-se pelo fato de já integrar pesquisas no celular para solucionar problemas de sala de aula ou aprimoramento de conteúdos. Destarte, em alguns momentos era perceptível que novas práticas estavam escondendo velhas metodologias, logo que as aulas, nesses momentos, fugiam do viés das práticas 
sociais como quando elementos semióticos importantes dos slides foram desconsiderados e o foco passava a ser, unicamente, a exposição do assunto.

Como afirmam Dudeney, Hockly e Pegrum (2016:68), "a melhor maneira de começar a explorar os novos letramentos e as tecnologias é começar devagar”, ou seja, o docente precisa iniciar aos poucos o percurso da inserção da tecnologia em suas aulas, principalmente os que ainda não se sentem muito confortáveis em usá-la, pois como é uma das exigências de um documento oficial e precisa ser cumprida, os professores necessitam ir se adequando quanto a isso, como os que estudamos estão tentando fazer.

Os dados nos mostram que ainda há pontos a melhorar com relação ao tema aqui tratado, mas o importante é dar o primeiro passo. Mesmo nosso estudo sendo realizado com dois sujeitos, conseguimos apreender muito a respeito de suas práticas letradas digitais em contextos reais de ensino, no entanto, há a necessidade de pesquisas futuras para tratar do assunto de maneira mais abrangente.

\section{Referências}

BARDIN, L. Análise de conteúdo. Lisboa: Edições 70, 1977.

BARTON, D.; LEE, C. Linguagem online: textos e práticas digitais. São Paulo: Parábola Editorial, 2015.

BRASIL. Base Nacional Comum Curricular (BNCC). Educação é a Base. Brasília, MEC/CONSED/UNDIME, 2017. Disponível em: 568 http://basenacionalcomum.mec.gov.br/images/BNCC_publicacao.pdf. Acesso em: 02 jun. 2019.

BUCKINGHAM, D. Cultura digital, educação midiática e o lugar da escolarização. Educação e Realidade, Porto Alegre, v. 35, n. 3, p. 37-58, 2010. Disponível em: . Acesso em: 24 jun. 2016.

BUZATO, M. Letramentos digitais e formação de professores. In: CONGRESSO IBERO-AMERICANO EDUCAREDE: EDUCAÇÃO, INTERNET E OPORTUNIDADES, 3, 2006, São Paulo. Anais... São Paulo: CENPEC, 2006, p. 1-13.

BUZATO, M. Desafios empíricos-metodológicos para a pesquisa em letramentos digitais. Trabalhos em Linguística Aplicada, Campinas, n. 1, p. 45-62, jan./jun. 2007.

CARVALHO, G. Eventos de letramento e práticas de letramento: teoria e prática nos Novos Estudos de letramento. In: MAGALHÃES, I. (Org.). Discursos e práticas de letramento: pesquisa etnográfica e formação de professores. Campina, SP: Mercado de Letras, 2012.

DAMICO, J.G.S. KLEIN, C. O uso da etnografia pós-moderna para a investigação de políticas públicas de inclusão social. In: MEYER, D. E.; PARAÍSO, M. A. Metodologias de pesquisas pós-críticas em educação. 2.ed. Belo Horizonte: Mazza Edições, 2014.

DUDENEY, G.; HOCKLY, N.; PEGRUM, M. Letramentos digitais. São Paulo: Parábola Editorial, 2016. 
GASPARIN, J.L. Uma didática para a pedagogia histórico-crítica. Campinas, SP: Autores Associados, 2007.

IBGE. Disponível em: https://www.ibge.gov.br/apps/populacao/projecao/. Acesso em: 11 jun. de 2019.

LIBÂNEO, J.C. Didática. $2^{\circ}$ ed. São Paulo: Cortez, 2013.

NOVA ESCOLA. Disponível em: https://novaescola.org.br/. Acesso em 23 de junho de 2020.

PRENSKY, M.. Digital Natives. Digital Immigrants.On the Horizon (MCB University Press, vol. $09 \quad \mathrm{n}^{\circ}$ 05) October, 2001. Disponível em: http://www.nnstoy.org/download/technology/Digital\%20Natives\%20-

\%20Digital\%20Immigrants.pdf. Acesso em: 20 jun. de 2020.

REZENDE, M. V., Formação Inicial de professores de língua portuguesa para a era digital. 2015. 230 f. Tese (Doutorado em Estudos da Linguagem) - Centro de Letras e Ciências Humanas, Universidade Estadual de Londrina, Londrina, 2015. Disponível em: . Acesso em: 26 jun. 2016.

O conceito de letramento digital e suas implicações pedagógicas. Texto livre: linguagem e tecnologia, Minas Gerais, vol. 9, $\mathrm{n}^{\circ}$ 1, p. 94-107, 2016.

RIBEIRO, M. H.; FREITAS, M. T. A. Letramento digital: um desafio contemporâneo para a educação. Educ. Tecnol. Belo Horizonte, vol. 16, n 13, p. 59-73, set./dez. 2011.

ROJO, R. Letramentos múltiplos, escola e inclusão social. São Paulo: Parábola Editorial, 2009.

Materiais didáticos no ensino de línguas. In: Moita-Lopes, L. P. (Org.) Linguística Aplicada na Modernidade Recente - Festschrift para Antonieta Celani. São Paulo, SP: Parábola Editorial/Cultura Inglesa, 2013, pp. 163-196.

STREET, B. Os novos Estudos sobre o Letramento: histórico e perspectivas. In: MARINHO, M.; CARVALHO, G. (Eds.). Cultura escrita e Letramento. Belo Horizonte: UFMG, 2010.

SCHONS, M. M.; VALENTINI, C. B. Movimentos de letramento digital nas práticas de leitura e escrita: um estudo de caso de uma criança do ensino fundamental. 2012. Trabalho apresentado no IX Seminário de Pesquisa em Educação da Região Sul, Caxias do Sul, 2012.

TORMENTA , A.A.; FIGUEIREDO, J.A. Planejamento: a importância do plano de trabalho docente na prática pedagógica. 2010. Disponível em: http://www.diaadiaeducacao.pr.gov.br/portals/cadernospde/pdebusca/producoes pde/20 10/2010_fafipa_ped_artigo_ana_aparecida_tormenta.pdf . Acesso em: 19 de dezembro de 2018 . 
VASCONCELLOS, C. S. Planejamento: projeto de ensino-aprendizagem e projeto político-pedagógico. 9 ed. São Paulo: Libertad, 2002.

YIN, R. K. Estudo de caso: planejamento e métodos. 2 ed. Porto Alegre: Bookman, 2001.

Recebido em 20 de maio de 2020

Aceito em 18 de junho de 2020 